\title{
Treatment modalities for hypersplenism in liver transplant recipients with recurrent hepatitis $C$
}

\author{
Lena Sibulesky, Justin H Nguyen, Ricardo Paz-Fumagalli, C Burcin Taner, Rolland C Dickson
}

Lena Sibulesky, Justin H Nguyen, Ricardo Paz-Fumagalli, C Burcin Taner, Rolland C Dickson, Division of Transplant Surgery and Transplant Hepatology, Division of Interventional Radiology, Mayo Clinic, 4500 San Pablo Road, Jacksonville, FL 32224, United States

Author contributions: Sibulesky L wrote and revised the paper; Nguyen JH designed the study and participated in writing and revising the manuscript; Paz-Fumagalli R and Dickson $\mathrm{RC}$ participated in the design and revising the paper; Taner $\mathrm{CB}$ participated in writing and revising the paper.

Correspondence to: Justin H Nguyen, MD, Division of Transplant Surgery, Department of Transplantation, Mayo Clinic, 4500 San Pablo Road, Jacksonville, FL 32224,

United States.nguyen.justin@mayo.edu

Telephone: +1-904-9563261 Fax: +1-904-9563359

Received: March 13, 2009 Revised: September 23, 2009

Accepted: September 30, 2009

Published online: October 28, 2009

\begin{abstract}
Hepatitis $\mathrm{C}$ is the most common indication for orthotopic liver transplantation in the United States. Unfortunately, hepatitis $C$ recurs universally in the transplanted liver and is the major cause of decreased graft and patient survival. The combination therapy of interferon and ribavirin has been shown to be the most effective therapy for recurrent hepatitis C. However, pre- and post-transplant hypersplenism often precludes patients from receiving the antiviral therapy. Splenectomy and partial splenic embolization are the two invasive modalities that can correct the cytopenia associated with hypersplenism. In this report we review the two treatment options, their associated outcomes and complications.
\end{abstract}

(c) 2009 The WJG Press and Baishideng. All rights reserved.

Key words: Hypersplenism; Leukopenia; Recurrent hepatitis C; Thrombocytopenia; Liver transplant

Peer reviewer: Paul Y Kwo, Professor, Gastroenterology and Hepatology Division, Indiana University School of Medicine, 975 West Walnut, IB 327, Indianapolis, Indiana 46202-5121, United States

Sibulesky L, Nguyen JH, Paz-Fumagalli R, Taner CB, Dickson RC. Treatment modalities for hypersplenism in liver transplant recipients with recurrent hepatitis C. World J Gastroenterol
2009; 15(40): 5010-5013 Available from: URL: http://www. wjgnet.com/1007-9327/15/5010.asp DOI: http://dx.doi. org/10.3748/wjg. 15.5010

\section{INTRODUCTION}

Liver disease caused by chronic hepatitis $\mathrm{C}$ virus (HCV) infection is the most common indication for liver transplantation in the United States. Unfortunately, HCV is universally recurrent in the transplanted liver and is a major cause of graft failure and decreased patient survival $^{[1]} \cdot 10 \%-30 \%$ of patients who have recurrent infection develop advanced fibrosis or cirrhosis within the first 5 years post-transplantation ${ }^{[2,3]}$.

The combination therapy of interferon and ribavirin has been shown to be the most effective therapy for HCV recurrence after liver transplantation with sustained virologic response rates between $20 \%-40 \%{ }^{[4]}$. Further studies are needed to determine whether treatment should be started preemptively, at the time of acute hepatitis, or at the early stages of chronic hepatitis in the graft. The ability to treat patients with adequate doses of interferon and ribavirin or even to initiate treatment is often limited by leucopenia, anemia, and thrombocytopenia. Chang et al[5] reported in their study that almost $50 \%$ of patients (109 out of 216) had a platelet count below $50000 / \mu \mathrm{L}$ before liver transplantation. At one year of follow-up, $21 \%$ of transplanted patients (45 out of 216) continued to have moderate to severe thrombocytopenia. Clinical factors associated with sustained thrombocytopenia were pretransplant severe thrombocytopenia $(<50000 / \mu \mathrm{L})$ and pretransplant large spleen volume $\left(>2000 \mathrm{~mm}^{3}\right)$.

Splenectomy and partial splenic embolization represent two interventional therapies to improve thrombocytopenia which could potentially allow treatment of HCV. In this review we examine the effectiveness and risks of these approaches in liver transplant patients.

\section{SPLENECTOMY}

Splenectomy has been performed routinely in the past in liver and kidney transplant patients for immunologic reasons. It allowed patients to tolerate azathioprine therapy for episodes of rejection ${ }^{[6]}$. This practice continued 
until the early 1980s when cyclosporine was introduced. Current accepted indications for post-transplant splenectomy include recurrent ascites, splenic infarction, large aneurysms of the splenic artery, thrombocytopenia secondary to hypersplenism prior to or after liver transplantation, and small-for-size syndrome in recipients of living donors with associated thrombocytopenia and impaired liver function. Splenectomy was also performed at the time of liver transplantation for $\mathrm{ABO}$ incompatibility and preemptive HCV treatment with interferon and ribavirin in thrombocytopenic patients ${ }^{[7-9]}$. Tashiro et al ${ }^{[10]}$ advocated performing concurrent splenectomy with liver transplantation in all patients who had a pre-transplant platelet count of less than $60000 \mathrm{~mm}^{3}$ so that this group of patients could tolerate preemptive administration of combination therapy in the post-transplant period.

Although successful results have been reported, splenectomy is potentially associated with multiple complications. It is an invasive procedure that can be technically difficult, with a high risk of bleeding in patients with portal hypertension, varices, and enlarged spleen. Portal vein thrombosis and pancreatic leaks requiring surgical reexploration have been described as complications ${ }^{[9,11]}$. However, in our opinion, the risk of infection post-splenectomy is the most serious and potentially life-threatening complication in the immunosuppressed population. Troisi et al ${ }^{[12]}$ reported that 4 out of 10 liver transplant patients who underwent splenectomy developed sepsis, which led to their demise. Samimi et al ${ }^{[13]}$ reported $17.5 \%$ vs $2.7 \%$ one-month and $30 \%$ vs $11.5 \%$ one-year sepsis-related mortality in patients who underwent concomitant splenectomy with liver transplantation $v$ s those who underwent liver transplantation alone. Neumann et al ${ }^{[14]}$ reported an increased risk for opportunistic pneumonia in patients who underwent simultaneous splenectomy and liver transplant. Splenectomy also places patients at risk for overwhelming post-splenectomy sepsis syndrome (OPSS), usually due to encapsulated organisms. It is recommended by the Center for Diseases Control to immunize patients prior to splenectomy to decrease the risk of OPSS from Streptococcus pneumonia, Haemophilus influenzae type B, and Neisseria meningitides ${ }^{[15]}$. According to guidelines issued by the American Society of Transplantation in 2004, these vaccines are administered to all candidates prior to liver transplantation ${ }^{[16]}$. Unfortunately, the response rate is only $40 \%-80 \%{ }^{[17,18]}$.

Despite vaccinations, fulminant bacterial sepsis carries a high risk of morbidity and mortality, especially in immunocompromised patients. The risk is greatest in the early months and years after splenectomy, but a period of as long as 45 years after the procedure has been reported in the literature ${ }^{[19]}$.

\section{PARTIAL SPLENIC ARTERY EMBOLIZATION}

Partial splenic embolization is a non-surgical, less invasive treatment of hypersplenism. It is usually performed via a percutaneous femoral artery approach. The embolization catheter is advanced into the splenic hilum as far as possible in order to avoid injury to the pancreatic circulation. Gelatin sponge slurry suspended in an antibiotic solution, coils, microspheres, and polyvinyl alcohol particles are used for embolization of approximate $60 \%-70 \%$ of spleen parenchyma. Splenic embolization procedures date back to 1973 , when the entire spleen parenchyma was ablated. At that time the procedure was associated with high rates of complications, including splenic abscesses, rupture, and pancreatic infarction, resulting in a high mortality rate ${ }^{[20]}$. Subsequently, this procedure became more successful with selective ablation of the spleen. In 1984, Mozes et $a l^{[21]}$ showed in a prospective randomized trial that partial splenic embolization was as effective as splenectomy for treatment in renal transplant candidates on hemodialysis with a low platelet count prior to administration of immunosuppression. In this study excessive infarction of the spleen was avoided with a mean of $65 \%$ of spleen parenchyma ablated. Partial splenic embolization is an effective method to reduce the platelet pool and improve platelet count and is greatly dependent on the infarcted splenic volume. Hayashi et $a^{[22]}$ reported that splenic volume was the best predictive factor for increase in platelet count at one month and one year in patients with liver cirrhosis and hypersplenism.

In several reports in the literature, partial splenic embolization has been described in patients after liver transplantation. It has been successful in patients with thrombocytopenia and recurrent $\mathrm{HCV}$ who were able to undergo treatment with interferon and ribavirin as a result of ablation ${ }^{[23-25]}$.

Most patients develop post-embolization syndrome, including symptoms of fever, left upper quadrant pain, pleural effusion, pneumonia, and atelectasis. Splenic abscesses and rupture are infrequent and are more commonly encountered and less tolerated by immunocompromised cirrhotic patients with a greater area of embolization ${ }^{[26]}$. The risk is greatly reduced with aseptic technique, antibiotic prophylaxis, and careful control of pain. Extent of embolization is important as well, with more complications following greater than $70 \%$ area of ablation. In partial splenic embolization, achieving the intended target embolization area remains challenging. Graded partial splenic embolization at several settings has been entertained in order to avoid excessive embolization and severe complications associated with it ${ }^{[27]}$.

\section{DISCUSSION}

Hepatitis $\mathrm{C}$ is the most common indication for liver transplantation in the United States and Europe, but unfortunately the virus almost always recurs with up to a third of patients developing cirrhosis within the first 5 years. Interferon and ribavirin therapy has been widely accepted as the treatment for recurrent disease. Cytopenia, including thrombocytopenia, which often 
afflicts liver transplant patients, leads to failure to initiate this antiviral regimen, dose reduction, or discontinuation of therapy, which ultimately decreases the likelihood of sustained virological response ${ }^{[28]}$.

Although, hemolytic growth factors, such as erythropoietin and growth colony stimulating factors, are used to counter the anemia and neutropenia associated with interferon and ribavirin treatment, there is no approved therapy for low platelet count in HCV infected patients.

A new group of synthetic thrombopoietic agents, including romiplostim and eltrombopag, have been found to be effective in stimulating platelet production ${ }^{[29]}$. In 2008, romiplostim was approved by the FDA for the treatment of thrombocytopenia in patients with chronic idiopathic thrombocytopenic purpura (ITP). These agents are now being investigated in clinical trials for the treatment of thrombocytopenia in cirrhotic patients with hepatitis $\mathrm{C}$ infection ${ }^{[30,31]}$.

\section{CONCLUSION}

Currently, splenectomy is the more popular choice of treatment for hypersplenism and thrombocytopenia. The question is whether it is the optimal choice. Partial splenic embolization is an alternative option that is often overlooked. It is less invasive and potentially carries fewer infectious complications since there is a remnant of functional splenic parenchyma remaining after the procedure. Although it diminishes with time, the risk of OPSS in asplenic patients is life-long. It carries a high mortality rate and therefore, we feel, other options should be seriously considered. Thus, further prospective studies are needed to investigate both modalities in this select group of patients.

\section{REFERENCES}

1 Forman LM, Lewis JD, Berlin JA, Feldman HI, Lucey MR. The association between hepatitis $C$ infection and survival after orthotopic liver transplantation. Gastroenterology 2002; 122: 889-896

2 Gane E. The natural history and outcome of liver transplantation in hepatitis $C$ virus-infected recipients. Liver Transpl 2003; 9: S28-S34

3 Prieto M, Berenguer M, Rayón JM, Córdoba J, Argüello L, Carrasco D, García-Herola A, Olaso V, De Juan M, Gobernado M, Mir J, Berenguer J. High incidence of allograft cirrhosis in hepatitis $C$ virus genotype $1 \mathrm{~b}$ infection following transplantation: relationship with rejection episodes. Hepatology 1999; 29: 250-256

4 Gordon FD, Kwo P, Vargas HE. Treatment of hepatitis C in liver transplant recipients. Liver Transpl 2009; 15: 126-135

5 Chang JH, Choi JY, Woo HY, Kwon JH, You CR, Bae SH, Yoon SK, Choi MG, Chung IS, Kim DG. Severe thrombocytopenia before liver transplantation is associated with delayed recovery of thrombocytopenia regardless of donor type. World J Gastroenterol 2008; 14: 5723-5729

6 Megison SM, McMullin ND, Andrews WS. Selective use of splenectomy after liver transplantation in children. J Pediatr Surg 1990; 25: 881-884

7 Jeng LB, Lee CC, Chiang $\mathrm{HC}$, Chen $\mathrm{TH}$, Hsu $\mathrm{CH}$, Cheng HT, Lai HC. Indication for splenectomy in the era of livingdonor liver transplantation. Transplant Proc 2008; 40: 2531-2533
8 Kato H, Usui M, Azumi Y, Ohsawa I, Kishiwada M, Sakurai H, Tabata M, Isaji S. Successful laparoscopic splenectomy after living-donor liver transplantation for thrombocytopenia caused by antiviral therapy. World J Gastroenterol 2008; 14: 4245-4248

9 Kishi Y, Sugawara Y, Akamatsu N, Kaneko J, Tamura S, Kokudo N, Makuuchi M. Splenectomy and preemptive interferon therapy for hepatitis $\mathrm{C}$ patients after living-donor liver transplantation. Clin Transplant 2005; 19: 769-772

10 Tashiro H, Itamoto T, Ohdan H, Fudaba Y, Kohashi T, Amano H, Ishiyama K, Takahashi S, Aikata H, Chayama K, Arihiro K, Asahara T. Should splenectomy be performed for hepatitis $C$ patients undergoing living-donor liver transplantation? J Gastroenterol Hepatol 2007; 22: 959-960

11 Settmacher U, Nüssler NC, Glanemann M, Haase R, Heise $\mathrm{M}$, Bechstein WO, Neuhaus P. Venous complications after orthotopic liver transplantation. Clin Transplant 2000; 14: 235- 241

12 Troisi R, Hesse UJ, Decruyenaere J, Morelli MC, Palazzo U, Pattyn P, Colardyn F, Maene L, de Hemptinne B. Functional, life-threatening disorders and splenectomy following liver transplantation. Clin Transplant 1999; 13: 380-388

13 Samimi F, Irish WD, Eghtesad B, Demetris AJ, Starzl TE, Fung JJ. Role of splenectomy in human liver transplantation under modern-day immunosuppression. Dig Dis Sci 1998; 43: 1931-1937

14 Neumann UP, Langrehr JM, Kaisers U, Lang M, Schmitz V, Neuhaus P. Simultaneous splenectomy increases risk for opportunistic pneumonia in patients after liver transplantation. Transpl Int 2002; 15: 226-232

15 Recommended adult immunization schedule: United States, 2009*. Ann Intern Med 2009; 150: 40-44

16 Guidelines for vaccination of solid organ transplant candidates and recipients. Am J Transplant 2004; 4 Suppl 10: 160-163

17 Davidson RN, Wall RA. Prevention and management of infections in patients without a spleen. Clin Microbiol Infect 2001; 7: 657-660

18 Kumar D, Chen MH, Wong G, Cobos I, Welsh B, Siegal D, Humar A. A randomized, double-blind, placebo-controlled trial to evaluate the prime-boost strategy for pneumococcal vaccination in adult liver transplant recipients. Clin Infect Dis 2008; 47: 885-892

19 Evans DI. Postsplenectomy sepsis 10 years or more after operation. J Clin Pathol 1985; 38: 309-311

20 Maddison FE. Embolic therapy for hypersplenism (Abstract). Invest Radiol 1973; 8: 280-281

21 Mozes MF, Spigos DG, Pollak R, Abejo R, Pavel DG, Tan WS, Jonasson O. Partial splenic embolization, an alternative to splenectomy--results of a prospective, randomized study. Surgery 1984; 96: 694-702

22 Hayashi H, Beppu T, Masuda T, Mizumoto T, Takahashi M, Ishiko T, Takamori H, Kanemitsu K, Hirota M, Baba H. Predictive factors for platelet increase after partial splenic embolization in liver cirrhosis patients. J Gastroenterol Hepatol 2007; 22: 1638-1642

23 Bárcena R, Gil-Grande L, Moreno J, Foruny JR, Otón E, García M, Blázquez J, Sánchez J, Moreno A, Moreno A. Partial splenic embolization for the treatment of hypersplenism in liver transplanted patients with hepatitis $C$ virus recurrence before peg-interferon plus ribavirin. Transplantation 2005; 79: 1634-1635

24 Chao CP, Nguyen JH, Paz-Fumagalli R, Dougherty MK, Stockland AH. Splenic embolization in liver transplant recipients: early outcomes. Transplant Proc 2007; 39: 3194-3198

25 Sohara N, Takagi H, Kakizaki S, Sato K, Mori M. The use of partial splenic artery embolization made it possible to administer interferon and ribavirin therapy in a liver transplant patient with fibrosing cholestatic hepatitis $\mathrm{C}$ complicated with 
thrombocytopenia. Transpl Int 2006; 19: 255-257

26 Sakai T, Shiraki K, Inoue H, Sugimoto K, Ohmori S, Murata K, Takase K, Nakano T. Complications of partial splenic embolization in cirrhotic patients. Dig Dis Sci 2002; 47: 388-391

27 Zhu K, Meng X, Qian J, Huang M, Li Z, Guan S, Jiang Z, Shan H. Partial splenic embolization for hypersplenism in cirrhosis: a long-term outcome in 62 patients. Dig Liver Dis 2009; 41: 411-416

28 Burra P. Hepatitis C. Semin Liver Dis 2009; 29: 53-65

29 Kuter DJ. Thrombopoietin and thrombopoietin mimetics in the treatment of thrombocytopenia. Annu Rev Med 2009; 60: 193-206

30 McHutchison JG, Dusheiko G, Shiffman ML, RodriguezTorres M, Sigal S, Bourliere M, Berg T, Gordon SC, Campbell FM, Theodore D, Blackman N, Jenkins J, Afdhal $\mathrm{NH}$. Eltrombopag for thrombocytopenia in patients with cirrhosis associated with hepatitis C. N Engl J Med 2007; 357: 2227-2236

31 Panzer S. Eltrombopag in chronic idiopathic thrombocytopenic purpura and HCV-related thrombocytopenia. Drugs Today (Barc) 2009; 45: 93-99

S- Editor Li LF L- Editor Webster JR E- Editor Lin YP 